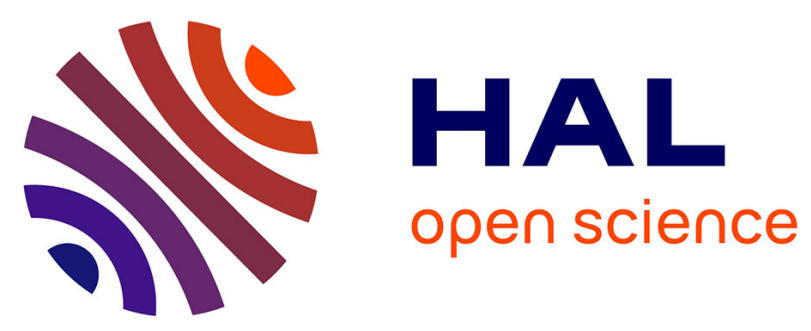

\title{
Catalyst-free three-component synthesis of highly functionalized 2,3-dihydropyrroles
}

Dong Wang, Linna Li, Hairong Feng, Hua Sun, Fabrice Almeida-Veloso, Marine Charavin, Peng Yu, Laurent Désaubry

\section{- To cite this version:}

Dong Wang, Linna Li, Hairong Feng, Hua Sun, Fabrice Almeida-Veloso, et al.. Catalyst-free threecomponent synthesis of highly functionalized 2,3-dihydropyrroles. Green Chemistry, 2018, 20 (12), pp.2775-2780. 10.1039/C8GC00987B . hal-01829592

\section{HAL Id: hal-01829592 \\ https://hal.sorbonne-universite.fr/hal-01829592}

Submitted on 4 Jul 2018

HAL is a multi-disciplinary open access archive for the deposit and dissemination of scientific research documents, whether they are published or not. The documents may come from teaching and research institutions in France or abroad, or from public or private research centers.
L'archive ouverte pluridisciplinaire HAL, est destinée au dépôt et à la diffusion de documents scientifiques de niveau recherche, publiés ou non, émanant des établissements d'enseignement et de recherche français ou étrangers, des laboratoires publics ou privés. 


\title{
Catalyst-Free Three-Component Synthesis of Highly Functionalized 2,3-Dihydropyrroles
}

\begin{abstract}
Dong Wang, ${ }^{a}$ Linna Li, ${ }^{a}$ Hairong Feng, ${ }^{a}$ Hua Sun, ${ }^{a}$ Fabrice Almeida-Veloso, ${ }^{b}$ Marine Charavin, ${ }^{b}$ Peng $\mathrm{Yu}^{\mathrm{a}}{ }^{\mathrm{a}}$ and Laurent Désaubry*a,b,c

An efficient synthesis of fully substituted 2,3-dihydropyrroles has been achieved in one step through the three-component reaction of amines, aromatic aldehydes and $\alpha$-ketoamides. This atom-economical and catalyst-free reaction is highly stereoselective and generates in a single step underexplored heterocycles. These compounds were examined in an enzymatic assay that led to the identification of potent $\alpha$-glucosidase inhibitors, thereby demonstrating the utility of this novel methodology in medicinal chemistry.
\end{abstract}

\section{Introduction}

Dihydropyrroles are a common structural motif found in a number of naturally occurring alkaloids and biologically active substances. ${ }^{1}$ In particular, 2,3-dihydropyrroles have been reported to be important precursors for the synthesis of a variety of natural products ${ }^{2}$ and other complex molecules. ${ }^{3}$ Several elegant methods have been reported for the synthesis of these compounds but each of these is restricted to limited types of substrates, and consequently deliver 2,3dihydropyrroles with a limited variety of substituents (Scheme 1). ${ }^{4}$ Herein, we report a highly efficient, one-step, stereoselective and green synthetic approach to 2,3dihydropyrrroles that display a novel pattern of substitutions using simple amines, aldehydes and easily accessible pyruvic amides as starting materials.

Three-component reactions are one-pot reactions that use three reagents to generate a single product containing most of the reagent atoms. ${ }^{5}$ Due to their atom-sparing and single-step nature, these reactions are extremely valuable in medicinal chemistry. ${ }^{6}$ The Doebner reaction is one of the oldest known three-component reactions. It generates substituted cinchoninic acids (or quinoline-4-carboxylic acids) from anilines, aldehydes and pyruvic acids (Scheme 2a). ${ }^{7}$ Since its discovery in 1887, only one article has been published

\footnotetext{
Sino-French Joint Lab of Food Nutrition/Safety and Medicinal Chemistry, China International Science and Technology Cooperation Base of Food Nutrition/Safety and Medicinal Chemistry, College of Biotechnology, Tianjin University of Science and Technology, Tianjin 300457, China. E-mail: desaubry@unistra.fr

${ }^{b}$. Laboratory of Therapeutic Innovation (UMR 7200), University of Strasbourg-CNRS,

Faculty of Pharmacy, 67400 IIIkirch, France

c. Laboratory of Biomolecules (UMR7203), Sorbonne University-CNRS, 4 place Jussieu, 75005 Paris, France

† Electronic Supplementary Information (ESI) available: Detailed experimental procedures, compound characterization, and NMR spectra. See DOI: $10.1039 / x 0 x \times 00000 x$
}

describing this reaction with a pyruvic amide. While the latter
Cyclocarboamination of alkynes (P.A. Wender, 2009)

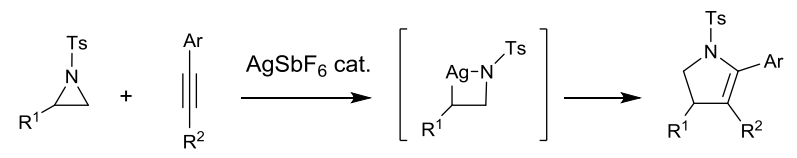

Intramolecular Pd"-catalyzed annulation ( T-P. Loh, 2017)

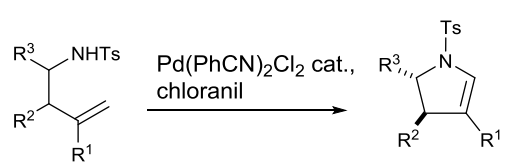

Cascade metallo-ene/Suzuki coupling reaction (H. Liu, 2017)

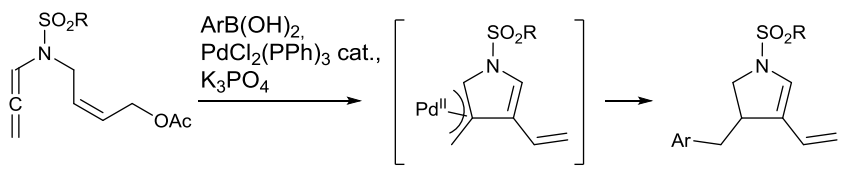

Rh-catalyzed condensation (M. Murakami, 2013)

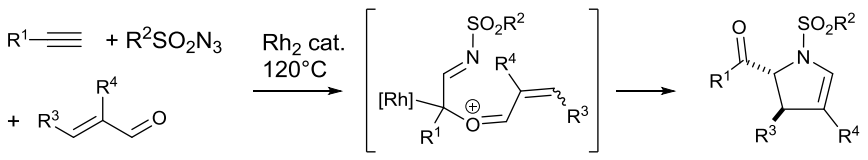

Cascade [2+2] cycloddition/rearangement (E. Vedejs, 1988)

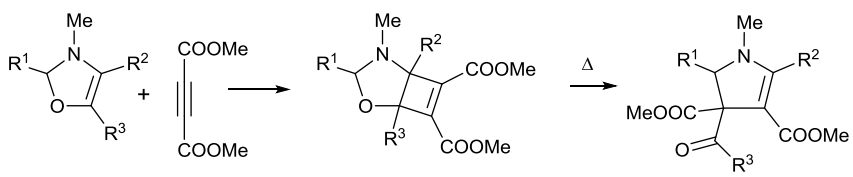

Cascade Michael addition/annulation (A. Lattanzi, 2015)

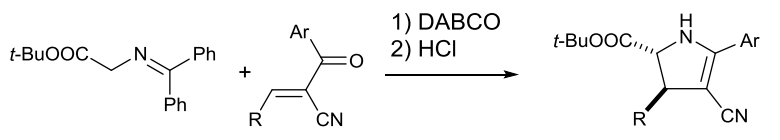

Scheme 1. Selected processes for the synthesis of 2,3-dihydropyrroles. 
a) Classical Doebner reaction

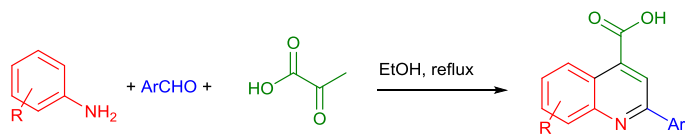

b) Doebner reaction using an immobilized pyruvic amide

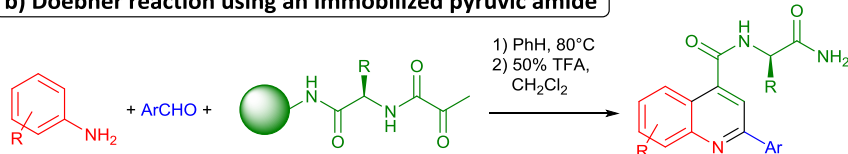

c) This work: five bonds formed in one step, green synthesis, simple SM

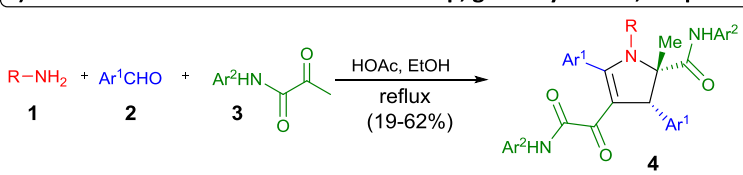

Scheme 2. a) A classical Doebner reaction, b) The sole published example of the Doebner reaction performed with a pyruvic amide ${ }^{8}$ and c) The unexpected formation of dihydropyrroles during an attempt to perform the Doebner reaction with a pyruvic amide in solution.

was immobilized on a Rink polystyrene resin (Scheme $2 b)^{8}$ the same reaction in solution has never been described to our knowledge.

\section{Results and discussion}

Unexpected divergent pathway of the Doebner reaction using a pyruvic amide instead of pyruvic acid

When we attempted to perform the Doebner reaction in solution, we were surprised to find that a 2,3-dihydropyrrole 4 was formed, rather than the expected cinchoninic amide (Scheme 2c). It seems likely that this reaction has been attempted during the last 130 years but the products obtained were probably discarded because they were difficult to identify. Indeed, we had to resort to X-ray crystallography to establish the structure of the product unambiguously. Given the originality of this reaction and its potential utility in both organic and medicinal chemistry, we decided to explore the scope and limitations of this novel three-component reaction.

In our initial study, p-anisidine (1a), p-tolualdehyde (2a) and pyruvic amide $\mathbf{3 a}$ were used to optimize the reaction conditions. We found that the solvent and the concentration significantly influenced the outcome of the reaction (entries 1 to 7, Table 1). Ethanol was shown to be superior to isopropanol or trifluoroethanol. The pyruvic amide was not completely consumed, so additional p-anisidine was added, but this resulted in a lower yield (entry 4). The product yield $(22 \%$, entry 8$)$ was similar in complete darkness, indicating that light has no effect on the reaction. We then investigated whether various acids could increase yields (entries 9 to 16).
PTSA, TFA and L-proline had deleterious effects, but a much higher reaction yield was obtained with acetic acid (entry 13 ).

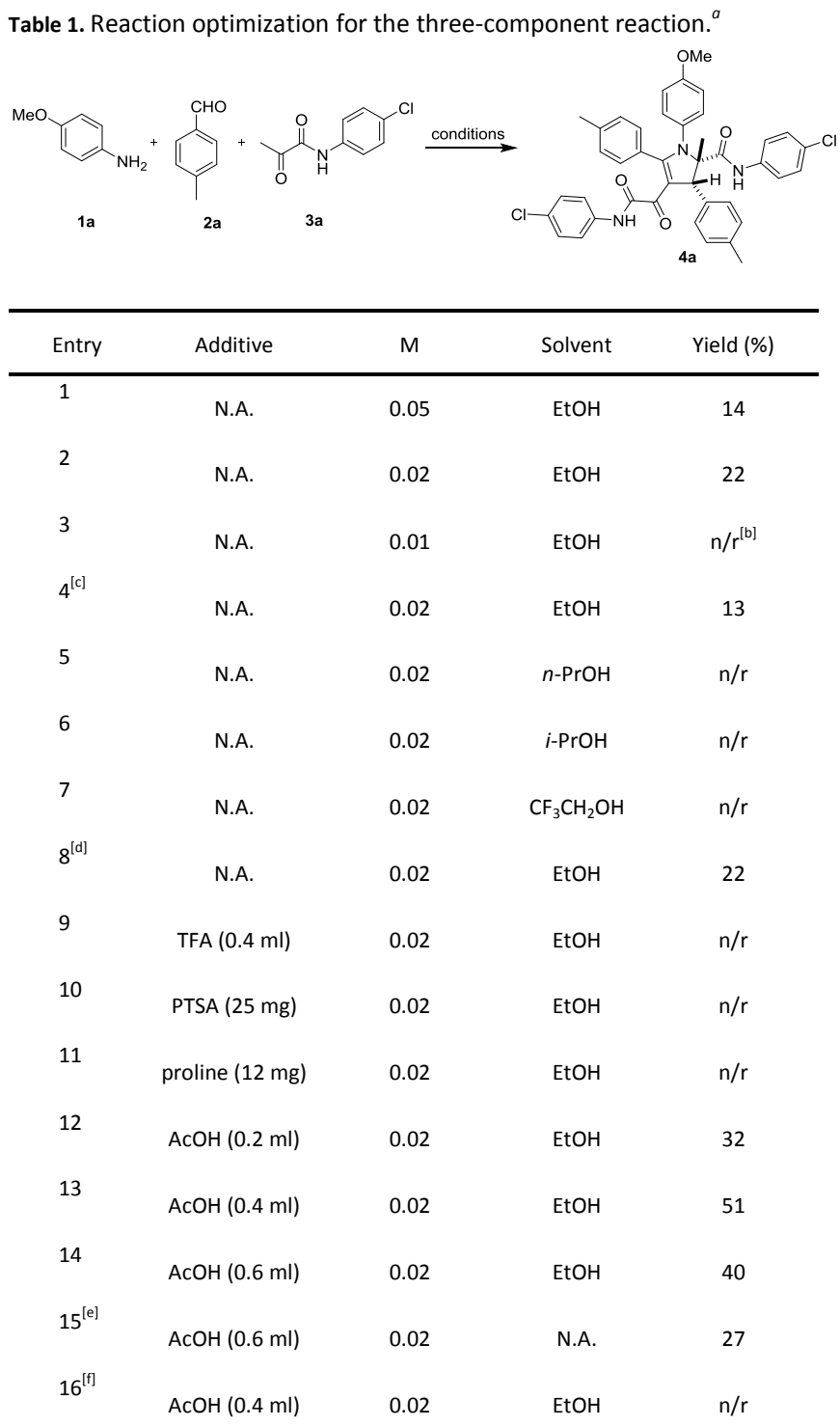

${ }^{a}$ Unless otherwise noted, all reactions were conducted at $0.025 \mathrm{M}(p$-anisidine concentration) with $p$-anisidine (1.0 equiv), $p$-tolualdehyde (2.0 equiv), and pyruvic amide (40 mg, 2.0 equiv) under reflux conditions. ${ }^{b}$ No reaction. Reaction run with $p$-anisidine ( 2.0 equiv), $p$-tolualdehyde ( 2.0 equiv), and pyruvic amide (40 mg, 2.0 equiv) under reflux conditions. ${ }^{d}$ reaction run in the dark. ${ }^{e}$ Reaction run in neat conditions. ${ }^{f}$ Reaction run under microwave conditions, temperature: $100^{\circ} \mathrm{C}$.

Running the reaction under neat or microwave conditions resulted in a large yield loss (entries 15 and 16). We therefore concluded that the best ratio of $\mathrm{p}$-anisidine, $\mathrm{p}$-tolualdehyde and $\mathbf{3 a}$ for this three-component reaction was $1: 2: 2$, in ethanol $(0.025 \mathrm{M})$ containing $\mathrm{HOAc}\left(\mathrm{V}_{\mathrm{EtOH}}: \mathrm{V}_{\mathrm{AcOH}}=12: 1\right)$ under reflux $(51 \%$, entry 13$)$. It is worth noting that only product $4 a$ having the cis configuration (as confirmed by NOE NMR experiments, see the Supplementary Information for details) was produced in this transformation. 
2:1) under reflux conditions. ${ }^{a}$ The reaction was done without any acetic acid.

\section{Reaction scope and limitation}

Using our optimized reaction conditions, we tested various amines (1), aldehydes (2) and pyruvic amides (3) (Scheme 3). Dihydropyrroles 4 were obtained with modest to good yields and with excellent diastereoselectivity (cis methyl and hydrogen) in all cases. Yields were highest for the chlorinecontaining aromatic pyruvic amides $\mathbf{4 a - c}$, whereas lower yields were obtained for the electron-rich or poor aromatic pyruvic amides, 4d-g. On the other hand, this reaction was not effective with aliphatic pyruvic amides as the adducts $\mathbf{4 h}$ and 4i were not observed. We then assessed the reactivity of various amines. The replacement of anisidine 1a with 4benzyloxy- or 4- phenyl aniline was slightly deleterious (4j: 37\%, 4k: $26 \%$ ), and the less nucleophilic 4-chloroaniline did not generate the expected adduct 4I. 1-Naphthylamine did not produce the adduct $\mathbf{4 m}$, indicating a sensitivity of this threecomponent reaction to steric hindrance. We found that $n$ butylamine efficiently yielded the expected product 4 n (51\%), demonstrating the suitability of aliphatic amines for this reaction. Benzylamine gave rise to 40 , but with a yield of only $28 \%$, confirming the sensitivity to steric hindrance of the amine. We were able to crystallize 40 and to confirm its structure by X-ray crystallography (Supplementary Information, part 4). For the aldehyde component 2, chloroand methoxy-benzaldehydes generated adducts $\mathbf{4 p - u}$ with yields between $30 \%$ and $40 \%$. Surprisingly, furfural gave rise to $4 \mathbf{v}$ with a yield of only 19\%, and all attempts to use cyclohexane carboxaldehyde were unsuccessful, suggesting that aliphatic aldehydes are not suitable for the production of cognate dihydropyrroles.

We extended the scope of this reaction by performing the reaction displayed in Scheme 3 with the addition of chalcone $5 a$ to the reaction medium (Scheme 4). The expected products, $\mathbf{4 b}$ and $\mathbf{6 a}$, were generated in a 1:1 ratio. These findings demonstrate that an enone resulting from aldol condensation between the pyruvic amide and the aldehyde is, indeed, an intermediate in the synthesis of dihydropyrroles 4 . We also

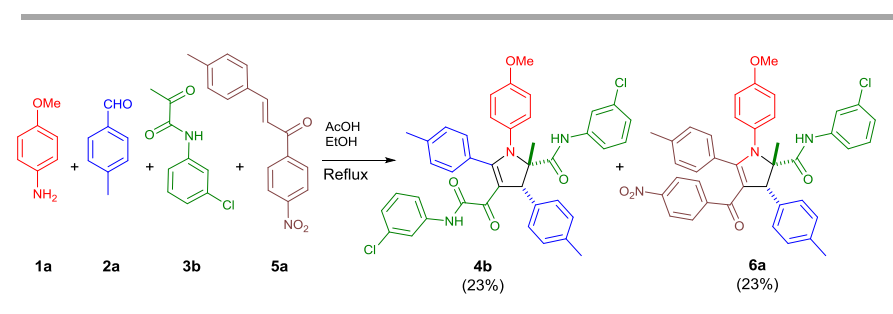

Scheme 4. Competitive Condensation in Presence of Chalcone 5a.

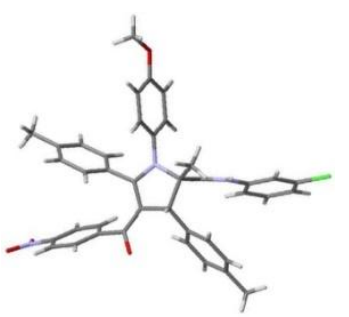




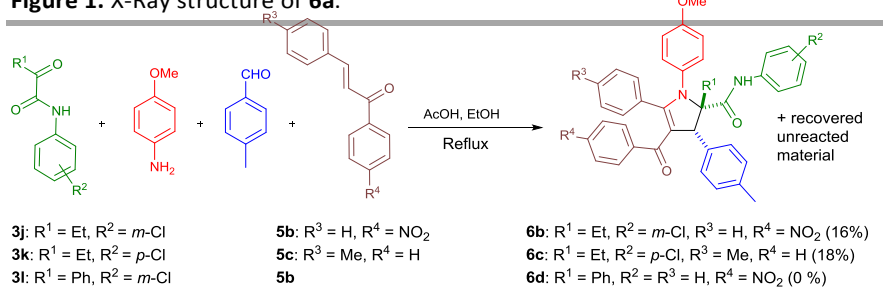

Scheme 5. Attempted condensation reactions with homopyruvic and phenylpyruvic amides $\mathbf{3 j - 1}$.

crystallized $\mathbf{6 a}$ and determined its structure unambiguously by X-ray crystallography (Figure 1).

Condensation of the sterically more demanding homopyruvic amide $\mathbf{3 j}$ and $\mathbf{3 k}$ with the chalcones $\mathbf{5} \mathbf{b}$ and $\mathbf{5} \mathbf{c}$ generated dihydropyrroles $6 \mathrm{~b}$ and $\mathbf{6 c}$ respectively, but phenylpyruvic amide $\mathbf{3 l}$ did not take part in this reaction, probably due to steric hindrance or to the requirement for an enolisable ketoamide (Scheme 5).

In order to obtain some insight into the reaction mechanism, we next examined whether Mannich base 7 could be an intermediate in the course of this reaction (Scheme 6). Heating together $p$ tolualdehyde, ketoamide $\mathbf{3 a}$ and Mannich base $\mathbf{7}$ did not deliver the adduct $6 \mathrm{e}$ but instead gave $4 \mathbf{a}$, probably via an elimination of 4anisidine, with concomitant formation of chalcone 5c and 4anisidine, which were then engaged in the three-component reaction. This observation strongly suggests that Mannich bases, such as 7, are not involved in the construction of the 2,3dihydropyrroles.

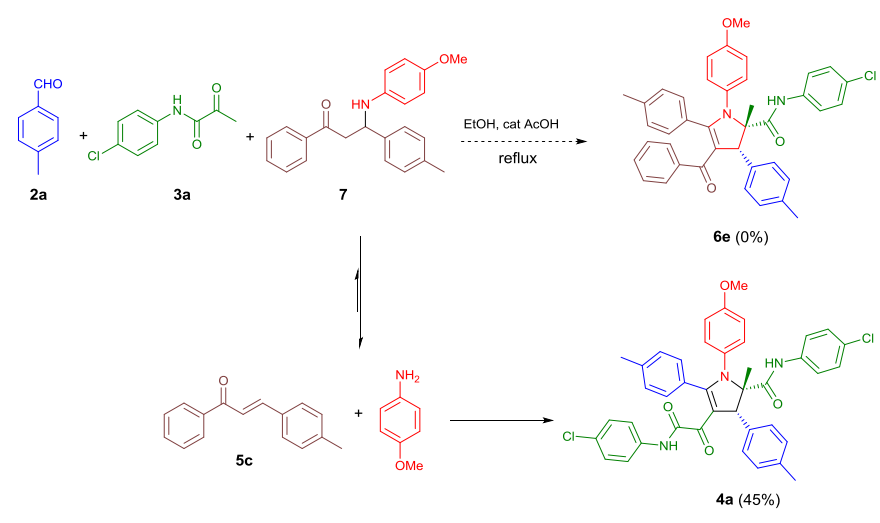

Scheme 6. Attempted condensation reactions with Mannich base $\mathbf{7}$ to generate adduct 6 e.

Based on our observations, we speculate that the formation of 4 involves imine 8 and enone 5 which react together to afford intermediate 9 (Scheme 7). Condensation with aldehyde 2 could lead to the 1,3-oxazine 11. Dehydration of this latter intermediate would then generate the iminium 12 which, upon deprotonation, affords the azomethine ylide 13 stabilized by $\pi$-stacking between the $\mathrm{Ar}^{1}$ and $\mathrm{Ar}^{2}$ moieties. This hypothesis would explain the requirement for an aromatic unit in the ketoamide 3 and the

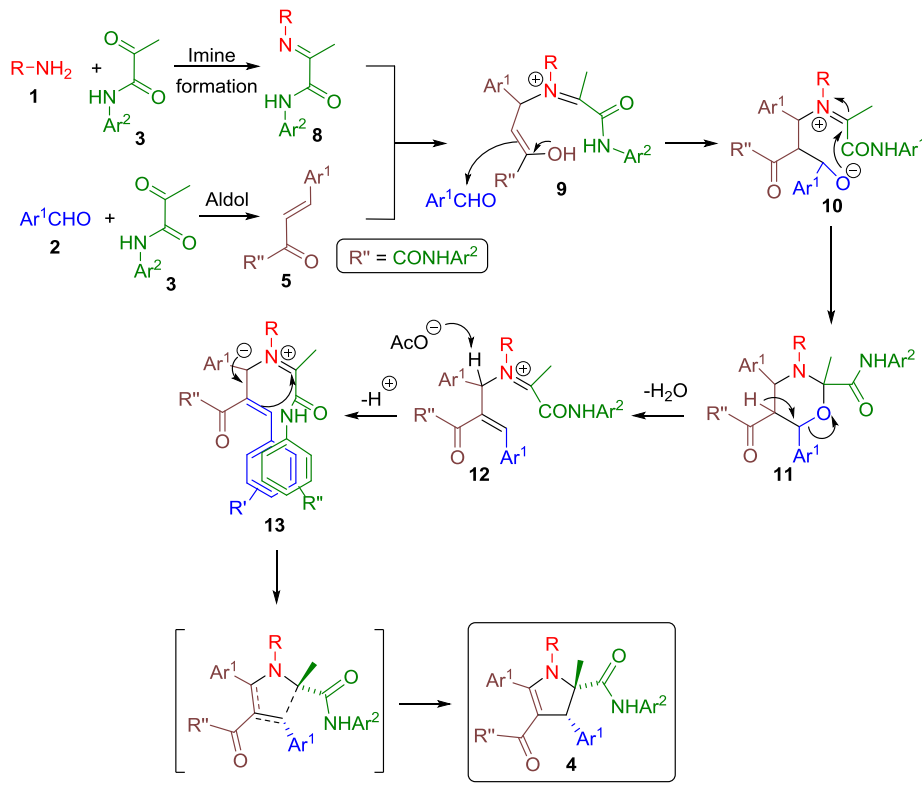

Scheme 7. Putative mechanism for the formation of dihydropyrroles 4.

observed stereochemistry of the adduct 4 . The intramolecular dipolar cycloaddition of azomethine ylides to form pyrrolidines has been widely studied. ${ }^{10}$ This approach has found utility in simplifying synthetic strategies to complex bioactive compounds. For this intramolecular process, the dipolarophile has been tethered to one of the carbon atoms or to the nitrogen atom of the azomethine ylide (respectively type I or type II, Scheme 8). To the best of our knowledge, no cycloaddition between a dipole and a dipolarophile directly connected together without any tether has been reported yet.

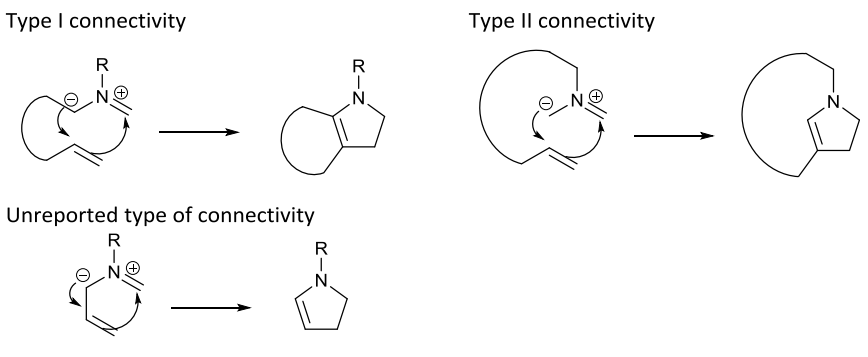

Scheme 8. Classification of intramolecular dipolar cycloaddition of azomethine ylides based on their connectivity. ${ }^{10}$

To validate the proposed mechanism we explored the possibility of directly condensing imine 8 with allylic alcohol 14a to directly generate intermediate 10a (Scheme 9). This first experiment did not deliver the expected adduct 16a, probably due to the insufficient electrophilic character of the ester. However, we were pleased to observe that replacement of this function by a nitro group successfully afforded the adduct $16 \mathrm{~b}$, in $19 \%$ yield, indicating that $10 \mathrm{a}$ is a likely intermediate in the mechanism. Going one 


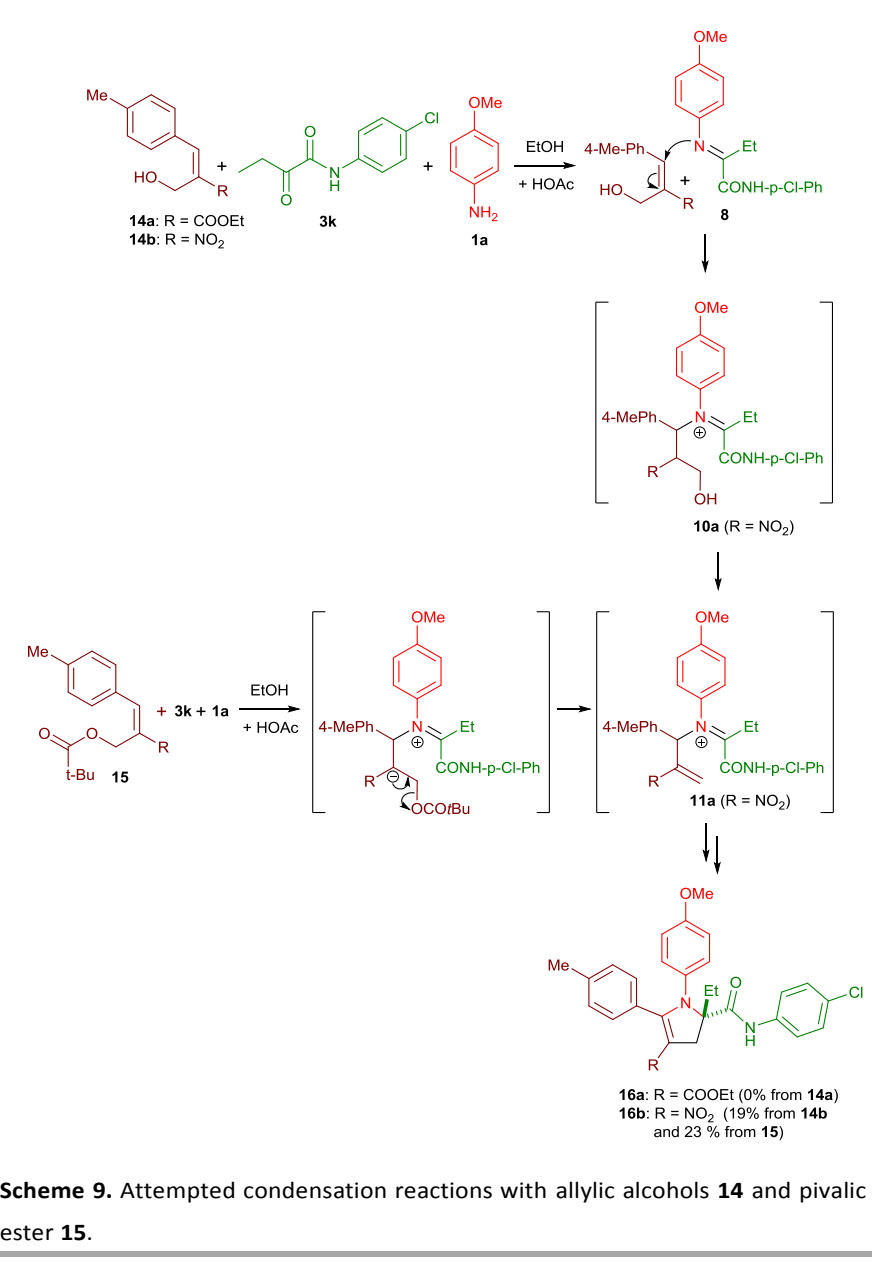

step further, we examined the pivalic ester 15 as a 1,3nucleophile, ${ }^{11}$ which also delivered the adduct $16 \mathrm{~b}$, revealing that 11a is also a probable intermediate. Furthermore, the aldol product $\mathbf{5}$ was isolated as a byproduct in the reaction. Altogether, these observations strongly support the mechanism proposed in Scheme 7.

The drug-like character of our 2,3-dihydropyrrole library prompted us to examine whether it could be screened in biological assays to identify new drug candidates. As a proofof-concept and based on our ongoing interest in the development of $\alpha$-glucosidase inhibitors, ${ }^{12}$ we determined whether 2,3-dihydropyrroles could inhibit this enzyme. Indeed, $\alpha$-glucosidase inhibitors, such as acarbose, are widely used to to treat type II diabetes, even though these agents display poor bioavailability and some adverse effects, such as bloating, intestinal spasm, abdominal pains and hepatic dysfunctions. ${ }^{13}$ Thus, there is currently an urgent need to develop novel antidiabetic $\alpha$-glucosidase inhibitors. The synthesized 2,3dihydropyrroles were screened for the inhibition of $\alpha$ glucosidase at the dose of $5 \mu \mathrm{M}$ and two hits, $4 a$ and $4 \mathbf{u}$ were found to inhibit this enzyme. Kinetic constants were then determined and compared to the standard inhibitor, acarbose.
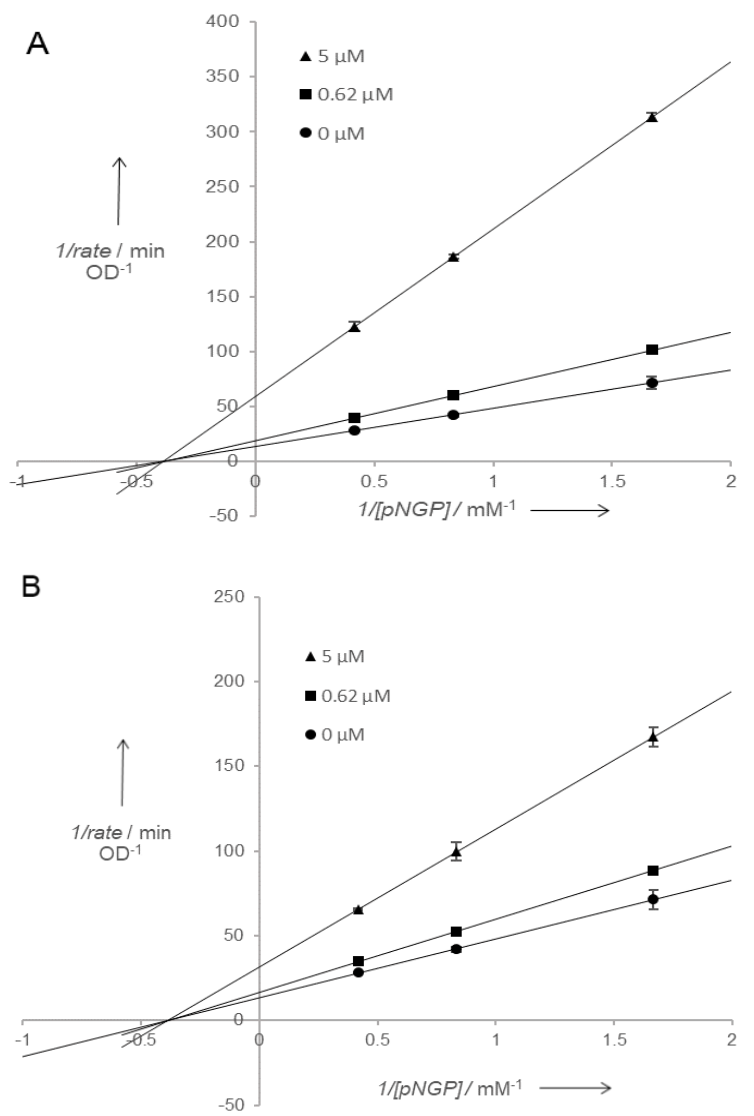

Figure 2. Lineweaver-Burk plot of the inhibition of $\alpha$-glucosidase by $4 a(A)$ and $4 u$ (B). Activities were determined with 4-nitrophenyl $\alpha$-D-glucopyranoside (pNGP) as a substrate.

Dihydropyrroles $\mathbf{4 a}$ and $\mathbf{4 u}$ were shown to be non-competitive inhibitors with Ki's of 2.4 and $3.5 \mu \mathrm{M}$, respectively (Figure 2), which blocked $\alpha$-glucosidase more efficiently than the standard competitive inhibitor acarbose (Ki of $320 \mu \mathrm{M}$, Supplementary Figure S4). This observation, associated with the drug-like character of $4 a$, suggest that these hits represent promising lead compounds for the development of novel antidiabetic agents.

\section{Conclusions}

In conclusion, we have discovered a useful reactivity of $\alpha$ ketoamides towards imines, generated in situ from amines and aromatic aldehydes. Ketoamides have previously been used in diverse multicomponent reactions ${ }^{14}$ but their reactivity in the present fashion has never to our knowledge been described. Remarkably, highly substituted dihydropyrroles were prepared in a single step, using three varied starting materials that are commercially available or easily accessible. Furthermore, the reaction was highly stereoselective, atom economic, and ecofriendly. To confirm its green chemistry character, we calculated that the atom economy and atom efficiency of the synthesis of $4 \mathrm{a}$ are respectively of 92.9 and $47.4 \% .{ }^{13}$ The reaction had only moderate overall yield but it was nevertheless remarkably effective given that it generated five new bonds ( $90 \%$ average yield per bond formation). Further mechanistic and synthetic studies on this new three- 
component reaction are underway. With the discovery that $\mathbf{4 a}$ and $\mathbf{4} \mathbf{u}$ potently inhibit $\alpha$-glucosidase, we have illustrated that this methodology is likely to prove very useful for the generation of drugs harbouring a new scaffold.

\section{Conflicts of interest}

There are no conflicts to declare.

\section{Acknowledgements}

Financial support from the National Natural Science Foundation of China (No. 81673296), the start-up Foundation from Tianjin University of Science \& Technology and Région Alsace for a Fellowship to MC is gratefully acknowledged. We thank Miss Haijuan Qin (TUST) for assistance with 2D NMR experiments.

\section{Notes and references}

1. (a) C. B. Cui, H. Kakeya and H. Osada, J. Antibiot., 1996, 49, 832835. (b) J. D. Leber, J. R. E. Hoover, K. G. Holden, R. K. Johnson and S. M. Hecht, J. Am. Chem. Soc., 1988, 110, 2992-2993. (c) I. V. Magedov, G. Luchetti, N. M. Evdokimov, M. Manpadi, W. F. A. Steelant, S. Van slambrouck, P. Tongwa, M. Y. Antipin and A. Kornienko, Bioorg. Med. Chem. Lett., 2008, 18, 1392-1396. (d) Y. Takeuchi, T. Inoue and M. Sunagawa, J. Antibiot., 1993, 46, 827832.

2. (a) S. B. Herzon and A. G. Myers, J. Am. Chem. Soc., 2005, 127, 5342-5344. (b) J. M. Humphrey, Y. Liao, A. Ali, T. Rein, Y.-L. Wong, H.-J. Chen, A. K. Courtney and S. F. Martin, J. Am. Chem. Soc., 2002, 124, 8584-8592. (c) R. Martin, A. Jäger, M. Böhl, S. Richter, R. Fedorov, D. J. Manstein, H. O. Gutzeit and H.-J. Knölker, Angew. Chem. Int. Ed. Engl., 2009, 48, 8042-8046. (d) J. Wegner, S. V. Ley, A. Kirschning, A.-L. Hansen, J. Montenegro Garcia and I. R. Baxendale, Org. Lett., 2012, 14, 696-699.

3. (a) C. Bressy, C. Menant and O. Piva, Synlett, 2005, DOI: 10.1055/s-2004-862386, 577-582. (b) P. Evans, T. McCabe, B. S. Morgan and S. Reau, Org. Lett., 2005, 7, 43-46. (c) N. Gigant and I. Gillaizeau, Org. Lett., 2012, 14, 4622-4625. (d) T. P. Pathak and M. S. Sigman, Org. Lett., 2011, 13, 2774-2777.

4. (a) B. Jiang, F.-F. Meng, Q.-J. Liang, Y.-H. Xu and T.-P. Loh, Org. Lett., 2017, 19, 914-917. (b) H. Liang, F. Yan, X. Dong, Q. Liu, X. Wei, S. Liu, Y. Dong and H. Liu, Chem. Commun., 2017, 53, 31383141. (c) T. Miura, T. Tanaka, K. Hiraga, S. G. Stewart and M. Murakami, J. Am. Chem. Soc., 2013, 135, 13652-13655. (d) P. A. Wender and D. Strand, J. Am. Chem. Soc., 2009, 131, 75287529. (e) G. Zhang, Y. Zhang, X. Jiang, W. Yan and R. Wang, Org. Lett., 2011, 13, 3806-3809. (f) S. Meninno, A. Capobianco, A. Peluso and A. Lattanzi, Green Chem., 2015, 17, 2137-2140. (g) E. Vedejs and J. W. Grissom, J. Am. Chem. Soc., 1988, 110, 32383246.

5. (a) R. P. Herrera and E. Marques-López, Multicomponent Reactions: Concepts and Applications for Design and Synthesis, Wiley-VCH Verlag GmbH \& Co. KGaA, 2015. (b) J. Zhu, Q. Wang and M.-X. Wang, Multicomponent Reactions in Organic Synthesis, Wiley-VCH Verlag GmbH \& Co. KGaA, 2014. (c) C. de Graaff, E. Ruijter and R. V. A. Orru, Chem. Soc. Rev., 2012, 41, 3969, 3969-4009. (d) J. Yu, F. Shi, and L.-Z. Gong, Acc. Chem. Res. 2011, 44, 1156-1171. (e) F. Shi, Z.-L. Tao, S.-W. Luo, S.-J. Tu and L.-Z. Gong, Chem. Eur. J. 2012, 18, 6885-6894. (f) F. Shi, G.J. Xing, R.-Y.i Zhu, W. Tan and Shujiang Tu, Org. Lett. 2013, 15, 128-131. (g) W. Dai, H. Lu, X. Li, F. Shi and S.-J. Tu, Chem. Eur. J. 2014, 20, 11382-11389. (h) W. Dai, X.-L. Jiang, J.-Y. Tao and F. Shi, J. Org. Chem., 2016, 81 , 185-192.

6. (a) R. W. Armstrong, A. P. Combs, P. A. Tempest, S. D. Brown and T. A. Keating, Acc. Chem. Res., 1996, 29, 123-131. (b) M. Colombo and I. Peretto, Drug Discov. Today, 2008, 13, 677-684. (c) A. Cores, C. Carbajales and A. Coelho, Curr. Top. Med. Chem., 2014, 14, 2209-2230. (d) A. Domling, W. Wang and K. Wang, Chem. Rev., 2012, 112, 3083-3135. (e) C. Hulme and V. Gore, Current Med. Chem., 2003, 10, 51-80. (f) G. Koopmanschap, E. Ruijter and R. V. A. Orru, Beilstein J. Org. Chem., 2014, 10, 544598. (g) M. Koszytkowska-Stawinska and W. Buchowicz, Beilstein J. Org. Chem., 2014, 10, 1706-1732. (h) M. A. Mironov, QSAR Comb. Sci., 2006, 25, 423-431. (i) S. Shaaban and B. F. Abdel-Wahab, Mol. Divers. , 2016, 20, 233-254.

7. (a) O. Döbner, Annalen, 1887, 242, 265-289. (b) O. Döbner, Ber., 1887, 20, 277-280. (c) M. M. Heravi, S. Asadi and F. Azarakhshi, Curr. Org. Synth., 2014, 11, 701-731.

8. A. Gopalsamy and P. V. Pallai, Tetrahedron Lett., 1997, 38, 907910.

9. S. Goudedranche, D. Pierrot, T. Constantieux, D. Bonne and J. Rodriguez, Chem. Commun., 2014, 50, 15605-15608.

10. I. Coldham and R. Hufton, Chem. Rev., 2005, 105, 2765-2809.

11. (a) P. Knochel and D. Seebach, Tetrahedron Lett., 1982, 23, 3897-3900. (b) D. Seebach, M. Missbach, G. Calderari and M. Eberle, J. Am. Chem. Soc., 1990, 112, 7625-7638.

12. (a) K. Han, Y. Li, Y. Zhang, Y. Teng, Y. Ma, M. Wang, R. Wang, W. Xu, Q. Yao, Y. Zhang, H. Qin, H. Sun and P. Yu, Bioorg. Med. Chem. Lett., 2015, 25, 1471-1475. (b) H. Sun, W. Ding, X. Song, D. Wang, M. Chen, K. Wang, Y. Zhang, P. Yuan, Y. Ma, R. Wang, R. H. Dodd, Y. Zhang, K. Lu and P. Yu, Bioorg. Med. Chem. Lett., 2017, 27, 3226-3230. (c) H. Sun, Y. Li, X. Zhang, Y. Lei, W. Ding, X. Zhao, H. Wang, X. Song, Q. Yao, Y. Zhang, Y. Ma, R. Wang, T. Zhu and P. Yu, Bioorg. Med. Chem. Lett., 2015, 25, 4567-4571. (d) H. Sun, D. Wang, X. Song, Y. Zhang, W. Ding, X. Peng, X. Zhang, Y. Li, Y. Ma, R. Wang and P. Yu, J. Agric. Food Chem., 2017, 65, 1574-1581. (e) H. Sun, Y. Zhang, W. Ding, X. Zhao, X. Song, D. Wang, Y. Li, K. Han, Y. Yang, Y. Ma, R. Wang, D. Wang and P. Yu, Eur. J. Med. Chem., 2016, 123, 365-378.

13. (a) Z. Liu and S. Ma, ChemMedChem, 2017, 12, 819-829. (b) H. A. Spiller and T. S. Sawyer, Am. J. Health Syst. Pharm., 2006, 63, 929-938.

14. F. Roschangar, R. A. Sheldonb and C. H. Senanayakea, Green Chem., 2015, 17, 752-768. 